\title{
Ethambutol toxic optic neuropathy: A case report and review
}

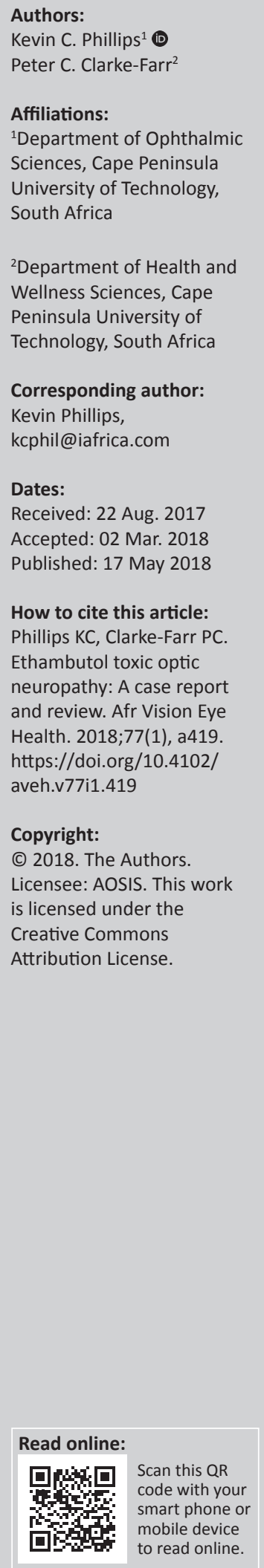

Authors:

C. Phillips'

Affiliations:

University of Technology,

${ }^{2}$ Department of Health and

Wellness Sciences, Cape

Peninsula University of

Corresponding author:

Kevin Phillips,

Dates:

Accepted: 02 Mar. 2018

How to cite this article: Phillips KC, Clarke-Farr PC. Ethambutol toxic optic Health. 2018;77(1), a419. https://doi.org/10.4102/ Licensee: AOSIS. This work is licensed under the Creative Commons Attribution License.
This article presents a case of ethambutol toxic optic neuropathy determined during the routine optometric examination of a 66-year-old man. Ethambutol is an established drug for the treatment of tuberculosis, but has significant side effects, notably optic neuropathy. The prognosis for vision restoration is unpredictable, with the possibility of permanent vision loss. Treatment cessation is the only option to limit ocular damage; therefore, the early recognition of ethambutol optic neuropathy by optometrists is essential.

\section{Introduction}

Although the global incidence of tuberculosis (TB) appears to be slowly decreasing, ${ }^{1}$ the World Health Organization (WHO) regards the disease as a major global health problem. ${ }^{2}$ Tuberculosis, because of infection with Mycobacterium tuberculosis, is said to cause an estimated 1.7 million deaths annually, while almost 9 million people contract the disease each year. ${ }^{3}$ The high numbers of deaths because of the disease occur despite mortality being preventable by timely and readily available and effective treatment. ${ }^{2}$ However, the improvement in treatment and the eradication of the disease have been hindered by the high prevalence of the human immunodeficiency virus (HIV), persisting global poverty and the emergence of highly drug-resistant forms of TB. ${ }^{1}$ Historically, there has been a reduction in the incidence of TB infections until the 1980s when the advent of HIV and acquired immunodeficiency disease syndrome (AIDS) saw a resurgence in TB infections, especially in the immunocompromised. ${ }^{4}$

Sub-Saharan Africa has been particularly affected by the high rates of HIV infection, where it is estimated that 8 out of every 10 HIV-infected adolescents reside..$^{5}$ For this reason, the HIV prevalence has resulted in an increase in the rate of TB infection in the region, accounting for $80 \%$ of the world's HIV-associated TB infections. ${ }^{3}$ South Africa has not escaped the scourge: Crowded township communities, poverty, substance abuse and malnutrition have contributed, along with the high-HIV prevalence, to TB being a leading cause of death in the country. ${ }^{6}$ In certain areas of Cape Town, the HIV rate is $20 \%$, whereas the TB notification rate is $2 / 100$ per year. $^{7}$ Although TB has been considered a disease of the lungs, it has now been found that the pattern of infection has changed, with a higher incidence of extrapulmonary disease now found. Extrapulmonary sites of infection commonly include the lymph nodes, pleura and osteoarticular areas, although any organ can be involved. ${ }^{4}$

Ethambutol (ethambutol hydrochloride) has been a long-established front-line drug in the treatment of TB, despite exhibiting toxicity. ${ }^{8}$ A major toxic effect of ethambutol is optic neuropathy. ${ }^{9}$ In combination with nephropathy, the optic neuritis is exacerbated because of the extended halflife of ethambutol. ${ }^{9}$ Optic neuropathy, especially retrobulbar optic neuropathy, resulting from ethambutol, is often unpredictable and dependent on treatment cessation, with variable resolution post-treatment. ${ }^{10}$

\section{Case report}

Mr T, a Caucasian male, aged 66, presented to the private practice he routinely attends on 08 June 2017, complaining of decreased vision at distance and near over the preceding 6 weeks. His current (progressive addition) spectacles, provided by this practice, were 11 months old and he reported no visual difficulties with them up until 6 weeks prior. Hehad been diagnosed with extrapulmonary TB (hip) in January 2017 and placed on Rifafour, a combination of four anti-TB medications (rifampicin, isoniazid, pyrazinamide and ethambutol). He was warned by his attending physician at the community clinic that the medication prescribed may have ocular side effects. Subsequent to his diagnosis of ethambutol toxic optic neuropathy (ETON) by an ophthalmologist, he was placed on Rifinah, which excludes ethambutol and pyrazinamide, for his continuing TB treatment, 
along with vitamin B and unspecified immunity booster vitamin supplements. His current medication consisted of Eltroxin (Levothyroxine) for hypothyroidism and an unspecified diuretic for hypertension. There was no other family medical history.

\section{Diagnostic data}

Best-corrected visual acuity (BCVA) distance (Snellen chart at $6 \mathrm{~m}$ ) was Right $6 / 12^{-2}$ and Left $6 / 15$. Near vision best corrected was N15 Right and Left and N12 both eyes. Ocular motilities were full smooth and accurate in both eyes with a penlight target. A slit-lamp examination revealed no conjunctival hyperaemia, and 3+/4 open angles (Van Herick), while an optic section indicated no lens opacification. Ophthalmoscopy revealed no disc or macular abnormalities in either eye. There was a marked gross central field defect on confrontation, the left eye more than the right, which was confirmed with a dense central pattern on the Amsler grid, again with the left eye more than the right. Generalised dyschromatopsia was evident, with no Ishihara pseudoisochromatic plates being identified correctly in either eye. Intraocular pressure measured with an Icare ${ }^{\circledR}$ Tonometer was Right $19 \mathrm{mmHg}$ and Left $19 \mathrm{mmHg}$ at 10:00.

The patient was referred to an ophthalmologist on an urgent basis, where the diagnosis of ETON was confirmed (Figures 1 and 2).

\section{Differential diagnosis}

Optic neuropathy is a frequent cause of vision loss, with diagnosis made on clinical findings. ${ }^{11}$ The clinical history indicates the possible aetiology of the optic neuropathy, where rapid onset is typical of demyelinating, inflammatory, ischaemic and traumatic causes, and a slower course is indicative of compressive, toxic or nutritional and hereditary causes. ${ }^{11}$

In order to accurately diagnose the disease, differential diagnoses need to be considered. Frequent causes of optic neuropathies include viral and bacterial causes, ischaemic optic neuropathies, demyelinating diseases, compressive or

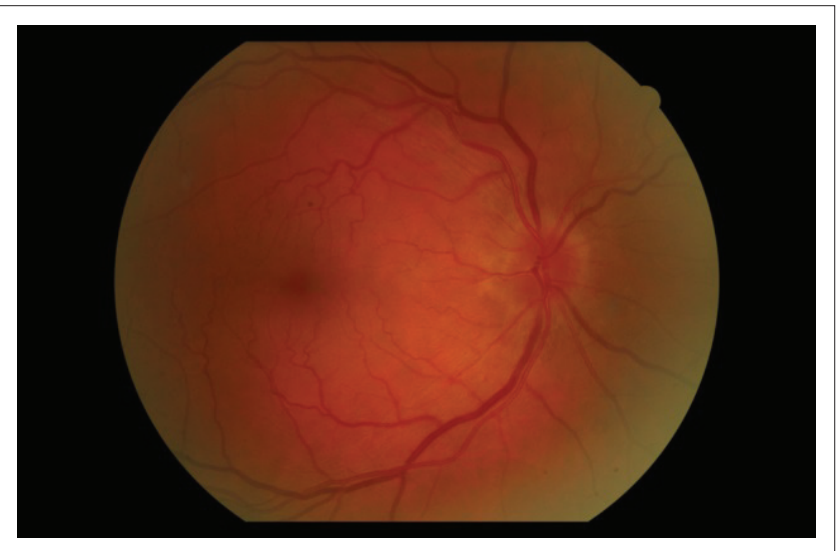

Source: Photograph by K.C.P. using Canon CR-DGi non-mydriatic fundus camera FIGURE 1: Right eye fundus photograph of patient with ethambutol toxic optic neuropathy.

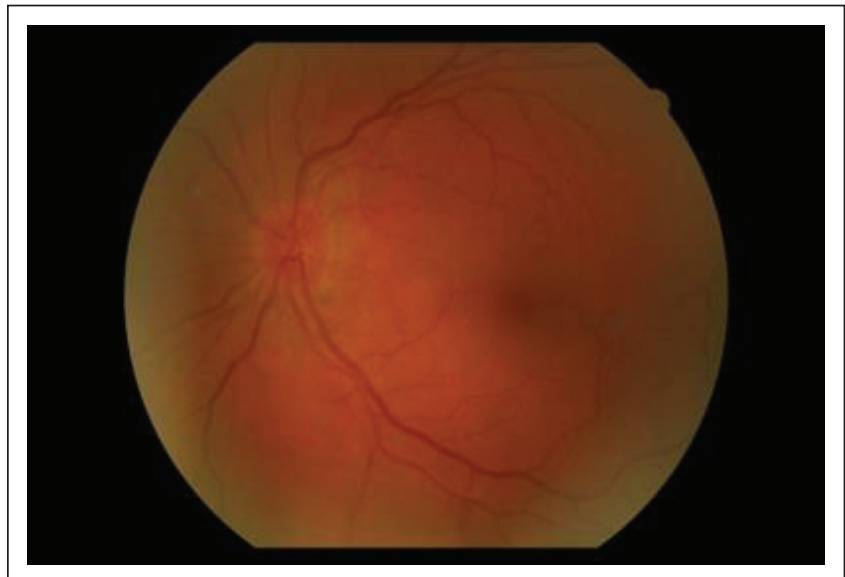

Source: Photograph by K.C.P. using Canon CR-DGi non-mydriatic fundus camera FIGURE 2: Left eye fundus photograph of patient with ethambutol toxic optic neuropathy.

infiltrative optic neuropathies, Leber's hereditary optic neuropathy and toxic and deficiency optic neuropathies. ${ }^{12}$

\section{Discussion}

Toxic optic neuropathy (TON) is a multifactorial condition that knows no boundaries of race, gender, geography or socio-economic status. ${ }^{12}$ It is typically painless, progressive, bilateral and symmetrical with a classic central or centrocecal scotoma and decreased visual acuity, often with attendant colour vision deficiency. Toxic optic neuropathy is also caused by damage to the optic nerve through different toxins, including drugs, metals, organic solvents, methanol and carbon dioxide. ${ }^{12}$ A similar clinical picture may also be caused by nutritional deficits, including B vitamins, folic acid and proteins with sulphur containing amino acids. Certain antimicrobial agents, antiepileptic drugs, ${ }^{13}$ antiarrhythmic drugs, drugs used to combat alcoholism, skin-lightening creams (hydroquinolones), antimetabolites, cancer treatments (tamoxifen) and erectile dysfunction preparations (sildenafil, Viagra ${ }^{\circledR}$ ) have been associated with optic neuropathy. ${ }^{12}$ Other drugs with potential, yet rare, vision-threatening neuropathy side effects include amiodarone, a potent antiarrhythmic agent that is used to treat ventricular arrhythmias, ${ }^{14}$ the anticonvulsant medication vigabatrin ${ }^{15}$ and even ibuprofen. ${ }^{16}$

Rifafour, a first-line treatment of TB, consisting of four antiTB elements (rifampicin, isoniazid, pyrazinamide and ethambutol) is prescribed for an initial 8-week period, following which a sputum test is undertaken. If the sputum test is positive for TB bacillus, a further 4-week course is normally prescribed. After the initial phase, a choice of several options for the continuation phase of either 4 or 7 months (a total of 6-9 months for treatment) is available. ${ }^{17}$ Rifafour presents as purple, round, film-coated tablets with recommended treatment dosages increasing based on the patient's body weight.

A visual prognosis with ETON is often devastating, with permanent visual field disturbances and colour vision deficiency. ${ }^{18}$ There is no known treatment for this form of TON 
other than drug cessation. ${ }^{19}$ This is in contrast to other causes of optic neuritis, where a post-treatment return of visual fields to normal after time is common. ${ }^{18}$ In the case of ETON, vision restoration prognosis is unpredictable, often resulting in some permanent vision loss which could be partial or severe. ${ }^{20}$ Treatment cessation appears to be the only option to limit ocular damage, and the early recognition of optic neuropathy is essential. Ophthalmic monitoring should be considered in all patients with ethambutol therapy. ${ }^{21}$

Because of the extremely high prevalence of TB in South Africa, and particularly in the Western Cape, many patients undergoing treatment of the disease will present for routine eye examinations, possibly unaware of the potential side effects of their medication. An awareness of the side effects of $\mathrm{TB}$ treatment and prompt and accurate recognition of the signs and symptoms of ETON by eye care practitioners can potentially prevent complete vision loss in susceptible individuals. All patients presenting with unexplained vision loss should be screened for the adverse effects of all medications, even if used for short periods. ${ }^{16}$ Colour vision evaluation and visual field testing using an Amsler grid should be a standard practice. Optical coherence tomography (OCT) is important in excluding other causes of vision loss because of neuritis or other aetiologies. ${ }^{20}$

\section{Conclusion}

The role of optometrists demands that they be at the forefront of primary vision care. The vast numbers of patients on $\mathrm{TB}$ treatment invariably result in such patients presenting for routine eye examinations. It is imperative that a thorough case history be conducted for each patient, including systemic and ocular disease history as well as prescribed medications. This is essential in being able to establish potential sightthreatening conditions because of drug toxicity, an important differential diagnosis in retrobulbar optic neuritis and every case of unexplained visual disturbance, even with the short-term use of medication. ${ }^{16}$

\section{Acknowledgements}

The authors would like to thank Dr Willem-Martin Gerber, ophthalmologist, for his diagnosis and prognostic opinion.

\section{Competing interests}

The authors declare that they have no financial or personal relationships that may have inappropriately influenced them in writing this article.

\section{Authors' contributions}

K.C.P. was the leader and primary contributor to the article. P.C.C-F. reviewed the article and provided input and guidance on the structure and article content.

\section{References}

1. Dheda K, Barry CE, Maartens G. Tuberculosis. Lancet. 2016;387(10024): 1211-1226. https://doi.org/10.1016/S0140-6736(15)00151-8

2. WHO. Global Tuberculosis Report 2013 [homepage on the Internet]. World Health Organization; 2013, p. 306 [cited 2017 Jun 22]. Available from: http://apps.who. int/iris/bitstream/10665/91355/1/9789241564656_eng.pdf

3. Lawn SD, Zumla Al. Tuberculosis. Lancet. 2011;378(9785):57-72. https://doi. org/10.1016/S0140-6736(10)62173-3

4. Golden MP, Vikram HR. Extrapulmonary tuberculosis: An overview. Am Fam Phys. 2005;72(9):1761-1768.

5. Adejumo OA, Malee KM, Ryscavage P, Hunter SJ, Taiwo BO. Contemporary issues on the epidemiology and antiretroviral adherence of HIV-infected adolescents in sub-Saharan Africa: A narrative review. J Int AIDS Soc. 2015;18(1):20049. https:// doi.org/10.7448/IAS.18.1.20049

6. Blaser N, Zahnd C, Hermans S, et al. Tuberculosis in Cape Town: An age-structured transmission model. Epidemics. 2016;14:54-61. https://doi.org/10.1016/j. epidem.2015.10.001

7. Bacaër N, Ouifki R, Pretorius C, Wood R, Williams B. Modeling the joint epidemics of TB and HIV in a South African township. J Math Biol. 2008;57(4):557-593. https://doi.org/10.1007/s00285-008-0177-z

8. Reynolds RC, Bansal N, Rose J, Friedrich J, Suling WJ, Maddry JA. Ethambutolsugar hybrids as potential inhibitors of mycobacterial cell-wall biosynthesis. Carbohydr Res. 1999;317(1-4):164-179. https://doi.org/10.1016/S0008-6215 (99)00069-5

9. Fang J-T, Chen $Y-C$, Chang M-Y. Ethambutol-induced optic neuritis in patients with end stage renal disease on hemodialysis: Two case reports and literature review. Ren Fail. 2004;26(2):189-193. https://doi.org/10.1081/JDI-120038521

10. Chan RYC, Kwok AKH. Ocular toxicity of ethambutol. Hong Kong Med J. 2006;12(1):56-60.

11. Behbehani R. Clinical approach to optic neuropathies. Clin Ophthalmol. 2007;1(3):233-246.

12. Kesler A, Pianka P. Toxic optic neuropathy. Curr Neurol Neurosci Rep. 2003;3(5):410-414. https://doi.org/10.1007/s11910-003-0024-y

13. Grzybowski A, Zülsdorff $M$, Wilhelm $H$, Tonagel F. Toxic optic neuropathies: An updated review. Acta Ophthalmol. 2015;93(5):402-410. https://doi.org/10.1111/ aos. 12515

14. Roff Hilton EJ, Hosking SL, Betts T. The effect of antiepileptic drugs on visual performance. Seizure. 2004;13(2):113-128. https://doi.org/10.1016/S10591311(03)00082-7

15. Mindel JS, Anderson J, Johnson $G$, et al. Absence of bilateral vision loss from amiodarone: A randomized trial. Am Heart J. 2007;153(5):837-842. https://doi. org/10.1016/j.ahj.2007.02.010

16. Plant GT, Sergott RC. Understanding and interpreting vision safety issues with vigabatrin therapy. Acta Neurol Scand. 2011;124(Suppl. 192):57-71. https://doi. org/10.1111/j.1600-0404.2011.01601.x

17. Gamulescu M-A, Schalke B, Schuierer G, Gabel V-P. Optic neuritis with visual field defect - Possible Ibuprofen-related toxicity. Ann Pharmacother. 2006;40(3): 571-573. https://doi.org/10.1345/aph.1G451

18. Lim SA. Ethambutol-associated optic neuropathy. Ann Acad Med Singapore. 2006;35(4):274-278.

19. CDC. TB Treatment [serial online]. CDC; 2014 [cited 2017 Aug 18]. Available from: http://www.cdc.gov/tb/topic/treatment/default.htm

20. Fang JP, Lin RH, Donahue SP. Recovery of visual field function in the Optic Neuritis Treatment Trial. Am J Ophthalmol. 1999;128(5):566-572. https://doi.org/10.1016/ S0002-9394(99)00297-4

21. Chuenkongkaew W, Samsen P, Thanasombatsakul N. Ethambutol and optic neuropathy. J Med Assoc Thai. 2003;86(7):622-625. 